\title{
CJAR
}

Canadian Journal of Action Research

Volume 22, Issue 1, 2021, pages 4-26

\section{SUPPORTING EARLY STUDY ABROAD STUDENTS IN ONTARIO: CASE STUDY OF A COLLABORATIVE ACTION RESEARCH INITIATIVE, WITH CONDITIONS CHANGING UNDERFOOT}

\author{
Sandra R. Schecter \\ York University \\ Nancy Bell \\ York University
}

\begin{abstract}
This article elucidates findings of an action research initiative that focused on the school engagement and social and cultural adaptation of a cohort of early study abroad students, aged 15-19, attending an urban secondary school in Ontario. The study was part of a federally sponsored partnership that supported the collaboration of postsecondary researchers with professionals working within a publicly funded organization. Despite challenges and disruptions to the schooling context, the team proactively pursued a strategy of developing students' resilience and self-advocacy skills while promoting their adaptation and acculturation to Ontario schooling and society. An agenda that fostered opportunities for faceto-face activities inside and outside class helped build social connections among international students and between students and staff that proved key to their academic engagement, cultural integration, and sense of well-being.
\end{abstract}

KEY WoRDS: Early study abroad students; English Language Learners; Intercultural education; International students; Secondary education

\section{INTRODUCTION}

This article elucidates findings of a collaborative action research initiative that focused on the school engagement and social and cultural adaptation of a cohort of early study abroad (ESA) students attending a public urban secondary school in Ontario, Canada. ${ }^{1}$ For the purposes of this research, the term early study abroad (ESA) students refers to international youths attending secondary school within a national context that is not their country of origin and being taught by individuals who have been socialized in a different language and culture than they have. The students, from different countries of origin and linguistic 
backgrounds, are part of a fast growing demographic of international students who have come to Canada for the purpose of obtaining an Ontario Secondary School Diploma.

Our study's original goals were: (a) To obtain an evidence-based portrait of what international/visa students and their teachers and administrators viewed as the cohort's major challenges in terms of language socialization, school engagement, and social and cultural adaptation; (b) To foster students' sense of agency and possibility by designing and executing a series of academic and social interventions that would assist with these youths' integration within the school community and Ontario society; and (c) To identify the pedagogical and extracurricular strategies that exerted a positive influence in facilitating students' academic engagement and sense of well-being. With the securing of a Partner Engage grant from the Social Sciences and Humanities Research Council of Canada, we also introduced an explicit fourth goal which was to undertake the above research agenda within a study framework that was consistent with the expectations of participatory action research (e.g., Kemmis \& McTaggart, 2005; Maguire, 1987; Schecter et al., 2021) that emphasizes community involvement in conceptualizing and executing a desired innovation.

As detailed below, we engaged a cohort of fee-paying students with a group of teachers, guidance counsellors, and administrators at an urban public school who were committed to identifying the challenges the students confronted and developing strategies that would support their academic success and social well-being.

In conceptualizing our project, we used two theoretical frameworks. The first, superdiversity, allowed us to situate our students as distinguishable from domestic "nationals" or "transmigrants" immersed in a process that involves a permanent move to a new country. The second theoretical perspective is one that would reconceptualize "literacy" more broadly to include-beyond the decoding and encoding functions of language-a set of skills necessary to facilitate the second-language socialization and cultural integration of international students. We were aware that the majority of extant research within these two frameworks does not align to the principles of participatory action research. This study constituted our best effort to remedy this lacuna.

\section{BACKground Literature on EARly STUdy Abroad Students}

In recent years, ESA programs for international students have become increasingly common in Ontario secondary schools. In 2018, there were 721,205 international students in Canada, including over 60,000 in the K-12 sector (Global Affairs Canada, 2019). Through study abroad programs, international students have become part of the Canadian educational and economic fabric: In 2016, Canada was the beneficiary of $\$ 21.6$ billion spent by international students on tuition, accommodation, and other living expenses (Global Affairs Canada, 2019). While in Canada the recruitment of international students is primarily undertaken by public and private educational instititutions, both the federal and provincial goverments have acknowledged the beneficial impact of this cohort on the national economy and Canada's global presence. The federal government supports international education initiatives by streamlining student immigration policies and investing in marketing strategies promoting Canada as a destination for international 
students (Global Affairs Canada, 2019). Similarly, in its International Education Strategy the Ontario Ministry of Education (2015) promotes "high-quality programs and services for K12 international students studying in Ontario" as a key goal (p. 22), citing as a priority cultural exchange where "international students get to know their domestic classmates" (p. 23) through intercultural group activities both in class and outside of school. The Ministry of Education elaborates its vision of interculturality as entailing "develop[ing] global competencies" (p. 20) and "identify[ing] opportunities to extend the classroom experience into a global context” (p. 21).

Various push and pull factors have made Canada a top choice for Asian students seeking to participate in study abroad programs. Globally, English has solidified its position as a dominant lingua franca (Canagarajah, 2007; Pennycook, 2010). The Englishes spoken in some parts of the world (e.g., the United Kingdom, the United States of America, Canada) are considered to reflect native speaker norms, thus providing their speakers with access to "global citizenship" (Heller, 2003) and positioning other dialect speakers as nonnative, or "inauthentic." Access to global citizenship via English education, coupled with difficult high school exit exams in China (Gaokao) that serve as a salient push factor, have created a situation where relatively large numbers of adolescent international students from China find themselves in Ontario high schools (Chen, 2017; Liu, 2016). Similarly, increasing numbers of European parents, most of middle-class backgrounds, are drawn to Canada as a schooling destination for their children (Tamtik, 2019). Their goal is to have the children develop "globally valued skillsets," including fluent English. Families of students from multiple national and linguistic backgrounds have cited the relatively uncomplex student visa application process as a reason for choosing Canada over the United States as a study destination (Tamtik, 2019).

Both nonnative speakers of English and noncitizens of Canda, these students often live in residences with host families with whom they have no previous relationship. Media coverage of some of the more dramatic fallout from this phenomenon has underscored that this student cohort experiences significant adaptation issues, including loneliness and disorientation, health problems, and disabling circumstances resulting from injudicious choices (e.g., Xing \& Zhou, 2018). Scholarly studies of youth who align to the ESA cohort indicate that these students face challenges with regard to academic, social, and cultural integration. Students report stories of social isolation and difficulties with linguistic and cultural adaptation (Kuo \& Roysircar, 2004, 2006; Nelson, 2013; Popadiuk, 2009, 2010; Popadiuk \& Marshall, 2011; Zheng, 2014). Kuo and Roysircar's (2006) quantitative survey of Taiwanese secondary students attending school in a large Canadian city found that a significant number of students felt "ill-prepared and not adequately orientated" (p. 159). Popadiuk $(2009,2010)$ documented a complex transition process for ESA students in Vancouver and noted, in particular, the pressures that they experienced from expectations of successful academic performance and extreme loneliness. Aware that they are considered separate from mainstream students and not well integrated into their host schools, at the same time these students are often neglected by their homestays (Yi, 2013), impeding their second-language and cultural socialization. Indeed, a study by health care professionals found that secondary students who live in homestays were more vulnerable 
to poor health outcomes, with female students at greater risk of sexual abuse and cocaine use (Wong et al., 2001).

\section{THEORETICAL FraMEWORKS}

Two theoretical frameworks served as conceptual undergirding for our research partnership. The first framework involves a re-visioning of the phenomenon of diversity in line with characteristics associated with recent trends in transnational migration and globalization, characteristics that yield cross-bordered communities (Blommaert \& Rampton, 2011; García, 2009). Within such a reconceptualization, sites localized within multilingual and multicultural societal contexts characterized by high levels of exchange of knowledge among cultures are considered to display a habitus of superdiversity, reflecting a host of characteristics associated with linguistic, cultural, and (trans)national identity (Blommaert, 2013; Vertovec 2007, 2010). Language practices figure prominently within such dynamic interplays of variables: the term plurilingualism has been used (e.g., Little et al., 2013) to characterize societal states where a diversification of languages is available and where individuals call upon multiple linguistic repertories as they "cross borders either physically or virtually" (García, 2009, p. 54). These conditions, it has been argued, allow for different linguistic forms and modalities, challenging traditional perceptions of languages as discrete entities by instantiating hybrid language uses as the norm (García, 2009; Gutiérrez et al., 1999). Within such superdiverse environments (as the one referenced in this article), it is not uncommon to find bilingual or multilingual individuals displaying language abilities that involve shifts between languages to accommodate the communication contexts and settings they find themselves in. Debate has centred on the appropriate representation of the linguistic phenomena exhibited by such individuals, specifically, whether they are engaged in code-switching (e.g., Poplack, 1980; Zentella, 1998), where speakers alternate between (generally) two codes or languages within a single conversation, displaying alternately the phonology and syntax consistent with each, or translanguaging (García, 2009), where a speaker's language resources are represented by a single, encompassing linguistic repertoire that combines or integrates two language systems that had previously been considered separate (e.g., García \& Wei, 2013). Either way, such flexible uses of different linguistic forms and modalities, it has been argued, serve to fundamentally transform social arrangements, instantiating hybrid language use as the norm (García, 2009; Gutiérrez et al., 1999).

Additionally, we learn from feminist, postcolonial, and sociolinguistic writings that categories such as where, when, and in what language individuals communicate are not determined a priori but rather are produced through people's interactions in particular situations of language and dialect contact (Bhabha, 1994; Butler, 1999; de Certeau, 1997; Eckert, 2000; Gupta \& Ferguson, 1997; Pratt, 1987; Spivak, 1993). Indeed, research on processes of language maintenance and shift within and across time has demonstrated that various enabling or constraining factors do not necessarily have the same effects for different actors from the same background, or even for the same actors at different times (Schecter \& Bayley, 2002, 2004). In situations of language contact, where speakers of different languages and persons of different and/or multiple identities interact, a condition Pratt (1987) has described as the "contact zone," a fair amount of online decision-making 
takes place that is not circumscribed by schematic behaviour related to generalizations about who speaks what language to whom. Instead, such decisions may have more to do with whether the kindly grocer whose shop one stops in quickly on the way to school to purchase a breakfast pastry speaks Vietnamese or English, or how weary or energized one is when provided the opportunity to participate in social situations in and outside of school. Furthermore, speakers position themselves in various ways, not only synchronically but also diachronically (over time), with respect to the languages and dialects to which they have access and the social groups with which they choose to affiliate. We therefore endorse Pratt's view that multilingualism should be studied less as a function of attributes of individual speakers and more in terms of interactional zones within which speakers work out social meanings and negotiate social differences (Pratt, 1987; Schecter, 2015). For these reasons, it would not be contradictory to find that, within traditional academic formats such as subject matter classes, ESA students gravitate to other students from the same linguistic and cultural backgrounds to achieve immediate transactional goals-e.g., understanding the expectations for a specific assignment-while at the same time public schooling has the capacity to create enabling conditions that open the door to greater degrees of creative agency and risk-taking on the part of these English language learners.

A second conceptual framework informing our study draws on sources often referred to as New Literacy Studies (Gee, 1999; Street, 1995; Street \& Leung, 2010). Conceptualizing literacy as an ideological construct in that both meaning and associated practices are based on social mores that have assumed hegemonic ascendancy over time, this perspective parts company with conventional views of literacy as comprising a series of independent, technical skills to be mastered. In this framework, the learning of a target language, and/or participation in literacy practices, is not viewed as as embodying a single referential value; rather, we acknowledge "multiple literacies" (Street, 1995), or social practices relating to engagement with information and understanding of meaning through the manipulation of different modes-linguistic, visual, gestural, tactile, and spatial. Given this framing, we considered reliance on a print-exclusive orientation (Street, 2005), associated with traditional schooling, to represent an unrealistic approach for youth who have not spent sufficient time in the host society to have accumulated the appropriate knowledge, or cultural capital (Bourdieu, 1977a, 1977b), needed to display culturally sanctioned linguistic forms (Rowsell, 2012). In consequence, this study supported the use of multimodal approaches in promoting second-language socialization. Therefore, while excavating the academic and cultural issues encountered by ESA students, our research team also explored different modes of semiotic mediation-speech, gesture, drama, digital technologies-that promoted teacher-student and student-student interaction within different learning spaces (e.g., Hull et al., 2010; Kress, 2002), with the goal of identifying strategies that show promise in facilitating the second-language acquisition and cultural adaptation of secondary-level international students. A focus on games that involved physical gesturing in addition to oral language use and learning activites involving use of Kahoot followed by class discussion constitute some examples of the integration of multimodal approaches within our team's action research strategy. Other multimodal strategies used both for teaching/learning purposes and for orienting students to the different school and board 
policies and protocols that would require their attention at specific times in the school year will be elaborated in the description of the study's findings to follow.

\section{Methodology: A Participatory Action Research Approach}

The study was part of a federally sponsored partnership that supported the collaboration of postsecondary researchers affiliated with an academic institution with professionals working within a publicly funded organization for the purpose of sharing knowledge, expertise, and capabilities in addressing a topic of common interest. In our preliminary meeting with prospective adult participants in January 2019, the project was introduced as a "participatory action research" (PAR) initiative, where participants in the setting are themselves actors in processes leading to educational change-this as a preferred response to challenges associated with unprecedented multilingual and multicultural diversity in systems of formal schooling (e.g., Cummins \& Early, 2011; Schecter et al., 2021). Also introduced were the study's original goals, as elucidated in the introduction to this article, within a framework of participatory action research (e.g., Gillis \& Jackson, 2002; Kemmis \& McTaggart, 2005; MacDonald, 2012; Maguire, 1987), where participants in the setting bring their experiences and social histories to bear on the articulation of the problem to be addressed and the determination of the actions to be taken (Timperley \& Lee, 2008) and project objectives and activities may be modified, or fine-tuned, to accommodate the setting's evolving needs (e.g., Johnson et al., 2018). Throughout our planning meetings, as new school-based colleagues expressed interest in joining the project, care was taken to underscore and reinforce the principles of PAR.

As it turned out, identifying a common set of goals among participants proved the least daunting of the project's challenges: from the start we all envisioned an innovation that involved implementing interventions that would be responsive to the language socialization needs of ESA students and create institutional capacity for fostering the schooling engagement and social integration of this student demographic. With regard to the participatory aspect, throughout we witnessed multiple examples of enacted co-agency on the part of university- and school-based members of the research team. A case in point where teacher collaborators significantly altered the direction of the research initiative involved a decreased emphasis on pedagogic strategies promoting second-language acquisition and an increased focus on social strategies designed to foster students' cultural integration and well-being. Participant agency as the project progressed was also reflected in students' initiatives in assuming greater responsibility for designing and facilitating workshop activities, as well as in publicizing planned events and recruiting other ESA students to join in them.

Some contextual information is important to frame the study. Between the time that the grant proposal was submitted (March 2018) and the start of the project (January 2019), approximately 8 months, the morale in public education in Ontario deteriorated rapidly, a result of increasingly strained contract negotiations between the government and teachers' unions, ultimately leading to "work to rule" and rotating strike actions which disrupted the study throughout 2019 and the 2 months preceding the pandemic in 2020. Indeed, it is a tribute to the ingenuity of our practitioner colleagues, who persevered in viewing the 
fostering of ESA students' school engagement as an important dimension of, rather than an addition to, their normal workload, that the project proceded and for the most part thrived. Still, there were times throughout the collaboration when obstacles resulting from diminished resources, staffing changes, and/or distancing of decisions from the local level presented as especially daunting. This said, we were able to maintain focus on our PAR agenda throughout.

\section{Site and Participants}

Our project was situated within Ravenswood (pseudonym) Secondary School, affiliated with a major public school board located within the Greater Toronto Area (GTA). The school boasts a diverse student body comprising many recent immigrants, $70 \%$ of whom speak a primary language other than English. International students and newcomers to Canada originate from more than 20 countries, primarily the Philippines, China, Iran, Turkey, South Korea, and Vietnam; 46\% have been in Canada for fewer than 5 years. The school offers Grades 9 through 12 of secondary level subject matter instruction, including compulsory English language and mathematics/numeracy courses as well as a wide spectrum of science, humanities, arts, and physical education courses and a French immersion program. With a student body of just under 900 students, Ravenswood registered a cohort of approximately 130 international students during the course of the 14-month research collaboration. These students were enrolled in Grades 9 through 12, and ranged in age from 14 to 20 .

Study participants included: two university-based researchers, the school's principal, two board-assigned guidance personnel (different for each of the 2 academic years), four secondary teachers who taught and interacted with international students on a regular basis, and a cohort of approximately 40 students aligning to the demographic under study, early study abroad (ESA) students at the secondary level who participated in project activities such as focus group discussions, workshops, and field trips.

\section{Data Collection and Analysis}

Data collection methods for the study included: hour-long interviews with six adult participants, comprising the four participating teachers and two guidance personnel; an hour-long focus group meeting with a subset of the 40 participating students for purposes of ascertaining the students' academic and social needs and garnering their responses to suggested project activities; 12 focus group meetings with eight participating educators for purposes of refining the goals of the project and designing strategic interventions and resources; and participant observation in collaborating teachers' classes (12) and at extraschool (e.g., day-long field trips) or extracurricular (e.g., special themed workshops, breakfasts, social events, or games hours) activities organized for the ESA cohort (12). Interviews with participating educators and student focus group meetings were audiorecorded. To accommodate participants' preferences, field notes and photographs were taken during the remainder of the events and activities outlined in this paragraph, including impromptu exchanges with students on field excursions. Further details about data collection are provided in Table 1. 
Table 1. Data Collection Summary

\begin{tabular}{|c|c|c|}
\hline Data collection activity & Details & Focus period \\
\hline Classroom observation & $\begin{array}{l}12 \text { classes: ESL, English, music, } \\
\text { geography }\end{array}$ & Jan. - May 2019 \\
\hline Interviews & $\begin{array}{l}\text { School principal, three board } \\
\text { administrators and five teachers }\end{array}$ & Jan. - May 2019 \\
\hline Educator focus groups & $\begin{array}{l}12 \text { meetings with five to six } \\
\text { professional educators }\end{array}$ & Jan. 2019 - Feb. 2020 \\
\hline Student focus group & 11 students & May 2019 \\
\hline $\begin{array}{l}\text { Extra-classroom } \\
\text { observation }\end{array}$ & $\begin{array}{l}\text { Field notes and video from student } \\
\text { workshops and presentation, group } \\
\text { sizes ranging from } 10 \text { to } 40 \text { students }\end{array}$ & May 2019 - Feb. 2020 \\
\hline Student feedback & $\begin{array}{l}\text { Exit slips, informal conversations on } \\
\text { field trips and at other organized } \\
\text { events }\end{array}$ & May 2019 - Feb. 2020 \\
\hline Ongoing dialogue & $\begin{array}{l}\text { Email correspondence with/among } \\
\text { teachers, principal, researchers }\end{array}$ & Jan. 2019 - Feb. 2020 \\
\hline
\end{tabular}

The study received full clearance-with approval for the data collection methods cited above-from both the Human Participant Reseach Committee of York University and the External Research Review Committee of the host school board. Appropriate informed consent protocols-including oral and written explanantions and elaborations-were provided to prospective participating teachers, school administrators, and students; and written consent from parents or guardians for students to participate in excursions was obtained for each study participant.

The project's methodology entailed a cyclical and recursive process (Boeje, 2010; Johnson et al., 2018) for data collection related to teachers' and students' perceptions of the issues confronting ESA students-involving observation and reflection, planning, implementation, and soliciting and collecting feedback from students and teachers. The analytic process specifically entailed sharing findings among co-researchers, identifying seminal themes and categories, revisiting mediational strategies and developing new elements of the project's interventionist component, and documenting the pedagogical and social frameworks that emerged over the course of the collaboration. By iteratively examining these data through a process of analytic deduction (Goetz \& Lecompte, 1984), we were able to bring into view differentiated approaches and strategies that promoted the academic engagement and social integration of international students at Ravenswood Secondary School. 


\section{STUDY Findings}

\section{Identifying ESA Students' Challenges}

During our initial discussions with teacher collaborators and students, and in a pilot study conducted by the principal author (Schecter, 2019), several recurring and overlapping themes emerged which guided the development of our interventionist strategy. ESA students often struggle with severe social isolation and cultural alienation. This condition is exacerbated by a lack of understanding of the cultural dimensions (traditions, regular activities, expectations for behaviour) of their new environment coupled with pressure to succeed academically within a short time period. We also noted that all of these issues were felt more acutely during transition times, such as the beginning of the year, the end of first semester, and the move from sheltered ESL courses to Academic stream offerings (with fewer language supports). Below we elaborate on each of the challenges summarized in this overview.

\section{Social Isolation}

Our findings from interviews, team meetings, and focus group discussion revealed that feelings of social isolation and loneliness proved significant problems for students (as reported in the research literature; e.g., Zheng, 2014). Although a few had forged relationships with "Canadian" students, these examples were considered exceptions and took time to develop. Given that many students arrive when they are already in their senior year, the window of opportunity for developing intercultural relationships is often a narrow one. Teachers observed that, for the most part, new ESA students tended to "cluster" with Ravenswood students from the same linguistic and cultural background while relying on virtual friendships with friends in home countries. They were not unfriendly with their Canadian peers and those from other countries, but most did not report forging close bonds. As one ESA student described, "the people in school are not your real friends." Another suggested that the term talkmates best described the relationship he had with other students in his classes. Asked to elaborate, the same student volunteered, "They help you get your work done," but the relationship does not extend beyond the classroom.

Several teachers noted that some students struggled to connect with students from any background. The negative impact of their social isolation started to become noticeable about 6 weeks into the semester. One teacher volunteered that she could see them "closing down," withdrawing into their phones, sleeping in class, and in some cases not coming to school at all. The anxieties were often heightened by the 2-week winter break, when many international students stay in Canada and must cope with no routine, no daily contact with peers, and lack of familiarity with Canadian holiday culture.

\section{Culture Shock}

Our students highlighted the challenges of navigating their way in an unfamiliar culture, especially during their first few weeks and months. In addition to the language barrier, they struggled with understanding how the transit system worked, learning how to do banking, figuring out how to sign up for medical insurance, discovering where it was safe to travel in the city, remembering which bin to use for their garbage versus recycling. In school, they found it daunting to choose courses, understand graduation requirements, adapt to daily 
routines, and learn about clubs and activities that were available to them. Even figuring out where to go for help proved problematic. While Ravenswood had three full-time guidance counsellors in addition to an itinerant part-time counsellor dedicated to international students, many new students were unfamiliar with the role of guidance personnel and were reluctant to seek help, at least during the intial days and weeks after arrival when they were required to make critical decisions. They regarded adults in offices as authority figures and did not feel comfortable approaching them. In addition, many reported not liking the food and being confused by traditions in homestays where diet and routines were different from what they were used to. It is worth noting that while all newcomers face similar issues, most have parents and siblings to rely on at the end of the day, while many in this cohort are in Canada on their own, without benefit of family and friends to help navigate an unfamiliar environment.

Teachers noted that ESA students often experienced a form of culture shock when interacting with students from other countries and were challenged to negotiate social and academic collaborations in the classroom. One teacher recounted a narrative of one student taking a pencil from another-treating this as a casual exchange that did not require formal permission. The owner of the pencil, however, was horrified and in tears at the perceived affront. Nothing like this ever would have happened in her country of origin, she explained in dismay to her teacher who was also a participant in our action research initiative. Our colleague intervened constructively to help negotiate a new understanding between the students regarding unspoken "social rules" of classroom co-participation.

\section{Pressure to Succeed Academically}

Adult and youth respondents consistently highlighted the degree of "intense pressure from home" students felt to succeed, and to do so quickly so as to avoid prohibitive schooling costs, while the barriers to success were numerous. Specific academic issues that surfaced included difficulties in: preparing and executing oral presentations; deciphering word problems in math; adjusting to unfamiliar assessment methods, particularly those emphasizing metacognitive understanding; and mastering subject-specific language demands. Both teachers and students flagged the end of the first semester, with impending challenges of culminating projects and exams in unfamiliar formats coupled with a foreign language, as a time of increased anxiety. As well, a majority of student respondents struggled with the transition from ESL to "mainstream" English courses, which require a command of an academic register that most students, including native English speakers, find demanding. This increased difficulty frequently resulted in students taking one or more (usually academic English) courses in a private school, which many considered to have less rigorous academic standards than the public system. This practice augmented the challenge of engaging them in the social and cultural life of the school. Finally, the demands of doing well academically were compounded by the need for ESA students to demonstrate their English proficiency on one of several externally administered international tests of English, recognized by Canadian universitites. Because these tests are not directly related to either the Ontario curriculum or the Ontario Secondary School Literacy Test (which all students must pass), they are not reviewed in class time. Rather, students must prepare for and arrange to take the tests on their own, compounding the pressure and adding cost. 


\section{Addressing ESA Students' Challenges}

In response to these challenges, our team organized a series of activities and programs for students. Notwithstanding the challenges of staff changes and mounting restrictions on activities, culminating in a board-wide shutdown because of the pandemic, we were able to implement a good number of targeted activities as we refined our definitions of the needs and addressed the concerns of this cohort. These included: a peer mentoring program, peer-led orientation days for new students at the beginning of each semester, field trips to local cultural landmarks, and monthly breakfast/lunch workshops on topics of interest (e.g., English proficiency test preparation). Findings from observations and interviews over the course of the 14-month project reinforced the importance of fostering face-to-face interaction with both peers and caring adults, fostering cultural knowledge through strategic multimodal activities designed to strengthen problem solving skills and enhance student resilience.

\section{Fostering Peer Relationships}

Teachers noted that the students who were most engaged in both school and community activities and events tended to face these perceived challenges with less trepidation. While several of our senior students felt that "getting involved" by joining clubs had helped them to make a smoother transition to Canadian schooling, these students proved the exception. Because earlier attempts to start international student associations, homework clubs, and other lunchtime and after-school activities had largely fallen flat, members of our team felt that students would benefit from more direct and guided intervention. On the basis of activities they had used previously with some success, several teachers hypothesized that sustained, strategic "connecting" activities would help students to form bonds and engage in school life. One teacher volunteered, "You can't just do one icebreaker: you need 5 to 10 days of activities in a row."

Building on these observations, we incorporated cooperative games and icebreaker activities into all the events we hosted, including orientation days, field trips, and workshops. These included team-based scavenger hunts, games that required physical cooperation, and small-group activities. In addition, we recruited returning senior students to serve as peer mentors and provided them with training in public speaking and facilitating small-group discussions using conversation starters and guided questions. During our first orientation day, we organized the students into small groups with peer leaders who spoke the same first language, which we encouraged them to use. This strategy proved effective, with many new students starting to open up during icebreaker exercises. By the end of the day, the students were running through the hallways, stopping briefly to pose for group selfies as they explored the building on a scavenger hunt. As our action research team stood back and watched these relationships begin to flourish, one colleague observed, "I know what they [the student mentors] are thinking: ... I wish that someone had been there for me."

\section{The Role of Caring Adults}

While developing peer-peer relationships was a priority, we were cognizant of the seminal role of the physical presence of caring adults in ESA students' daily lives. In our focus group 
with participating students, youths who had initially reported a reluctance to reach out to adults whom they perceived as authority figures recounted narratives of instances where such individuals had been both responsive and helpful. Students mentioned the names of individual teachers whose classrooms provided a safe and welcoming retreat from a cafeteria filled with unfamiliar faces, homestay family members who were supportive and caring (though not many), and guidance counsellors who were available for academic and wellness counselling. Ravenswood's principal, who normally deferred to our team members with regard to the planning of project activities, emphasized that such relationships between caring adults and ESA students needed to be openly solicited and orchestrated: they were too important-too dispositive-to leave to chance.

In response, our teacher collaborators sought out and maximized opportunities to introduce ESA students to adults in various positions throughout the schooling infrastructure. This goal was abetted through interactive games such as an online "who's who at school," a scavenger hunt that propelled students to interact with adults such as the librarian or janitor who were strategically positioned through the the building, and a "helping hands" exercise that required students to identify and get contact information for five caring adults they could contact in times of difficulty. In this manner, we tried to create a climate where students were positively disposed to seek support from knowledgeable and sympathetic individuals within the schooling environment. We also asked our student mentors to follow up on this initiative by introducing the topic in discussion with new students in breakout sessions during orientation workshops. Indeed, in their exit slip comments, a majority of students confirmed that the presence and good will of caring adults was one of the most important gains of their participation in the project: "I'll know someone I can call if I need help." "[I have a place] where I can go if I am sad."

Not surprisingly, the teachers involved in our action research initiative were strategic in maximizing opportunities for student engagement. They were well aware that while the response to the team's various activities was overwhelmingly positive, getting students to attend these events was a challenge given the various pressures in their lives. On the day of a given event, teachers and/or guidance counsellors would seek out individual students in their classes to remind them of the planned activity and encourage them to attend. Additionally, when opportunities presented in classes, teachers took time away from planned curricular lessons to help students acculturate to their New World circumstances. A music teacher upended her lesson plan when ESA students expressed confusion about what they were expected to do the following day, which student councils throughout Ontario had designated as a "walkout" day to protest government cutbacks and support teacher union demands. Apparently, the school's student representatives had planned a protest in front of their member of provincial parliament's office; and so Ms. Zuritsky (pseudonym) initiated discussion of the considerations involved in participating in such an event. When students expressed interest in attending the protest, she scrapped her planned music lesson and assisted them in procuring materials (cardboard, markers, sticks) needed to create placards that would express their views on the current state of education in the province. Of course, the exercise had implications for literacy learning, abetted by an impromptu lesson on slogans that resulted in gems such as "We need classes, not cutbacks" 
and "Don't hurt our chances." (The lead author had suggested "ruin," but students opted for the less hyperbolic "hurt.")

\section{Orienting Students to School and City}

As reported in the secondary literature (Kuo \& Roysircar, 2004, 2006; Popadiuk, 2009, 2010), ESA students found it difficult to navigate an unfamiliar physical and cultural environment. Our team found that two factors exacerbated this challenge-timing and communication mode. A great deal of information regarding school policies (e.g., graduation requirements, visa renewal guidelines, accessing insurance) is presented to students, mostly in dense English print, either before they begin school or in a welcome package they receive on the first day. Not surprisingly, given the volume and reliance on (English) print in these communications, this barrage of information can be overwhelming.

On the basis of data gathered from our student focus group and input from student mentors, we assembled a package of helpful information about Toronto in general and board and school protocols in particular. As much as possible we avoided relying exclusively on print materials or spoken presentations by adults. For example, to complement the vast amount of information available in print about visa renewals, visa requirements and tuition payments, generally available only on request, we prepared a simple poster with visuals and minimal text and posted it in ESL classrooms and other places where students were likely to see it (see Figure 1).2

Similarly, our "welcome package" relied almost exclusively on images with white space for students to input their own notes and translations. Rather than have adults present this information in scripted English, we placed students into small groups with mentors who spoke the same language and encouraged them to bring their personal experiences to bear on the discussion. We used games that involved physical gesture as well as spoken and print language in our icebreaker activities. One exercise had students creating paper airplanes with their names printed on them. When they sent their airplanes flying around the room, other students had to retrieve each one and identify its owner. To reinforce some of the roles of adults in the school, we used the ubiquitous cell phone for a Kahoot game, a scavenger hunt through the two-storey, multiwinged school building using colour-coded stickers and symbols to assist in wayfaring and group photos with key individuals. We could not anticipate all that students would need to know about their new schooling environment, but we were successful in heightening their sense of confidence in finding their way through the building and gaining a sense of the current practices and functions associated with the different locales. Senior students were the most effusive about the usefulness of these activities: several who had been at the school for a number of years reported learning new facts about both the physical structure and the services available, such as the existence of a school "bistro" that served free breakfasts every morning.

To address the issue of acculturation into the broader community, our team organized field trips focused on the history, geography, and culture of the city of Toronto and the province of Ontario. While our student participants reported being comfortable leaving the local neighbourhood for weekend excursions, we discovered that they largely confined their 
exploration of Toronto to shopping expeditions in downtown malls. Two popular field trips featured stalwarts of Toronto's recent and distant past and Ontario's agricultural legacy. The first, a walking tour of the historic St. Lawrence Market neighbourhood, included a "pub" lunch and a generous amount of free time to explore the various ethnic offerings (e.g., pierogi, babka, karnatzel) of the market. On our second field trip, to the Royal Agricultural Winter Fair, students (and teachers) enjoyed learning about the variety of animals and agricultural practices in the province by responding to "trivia" (a new word for many) quizzes and sampling traditional Canadian fare (e.g., butter tarts) for the first time. While these excursions raised student awareness of seminal aspects of the history and geography of Canada, the team viewed their true value as lying in reinforcing the interpersonal relationships the project had sought to foster throughout the year. As a member of our action research team remarked, "The best part is the time they spend talking to each other and us on the bus."

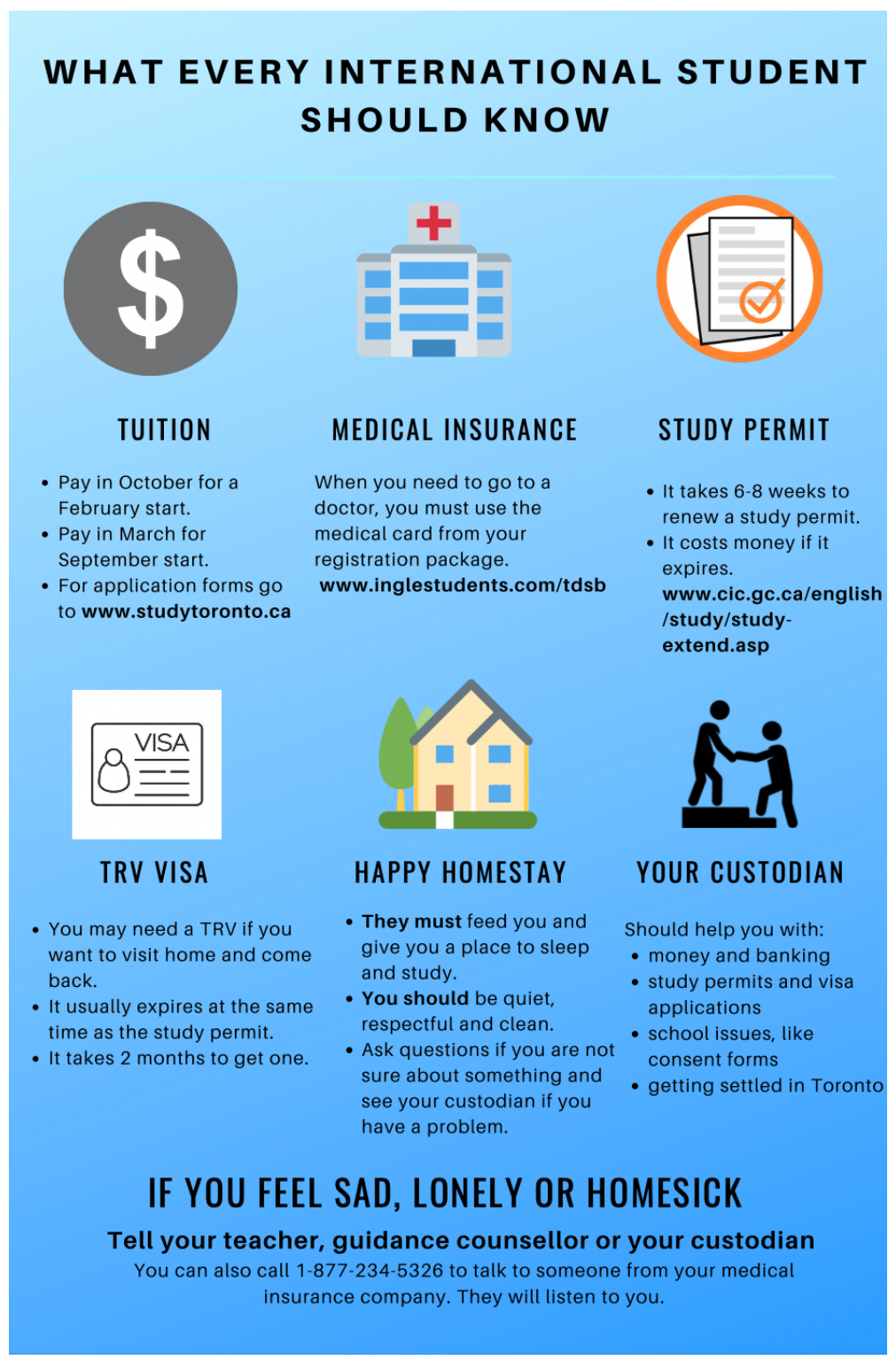

Figure 1. ESA Student Information Poster 


\section{Cultivating Resourcefulness}

As noted, one of the recurring themes expressed by students and teachers was the enormous pressure ESA students felt to succeed academically and secure their place in a Canadian postsecondary institution-as quickly as possible. Although some of our plans to address this issue did not materialize because of the disruption of the academic year, we did initiate a few interventions designed to reinforce students' problem-solving skills and confidence. For example, we hosted a lunchtime workshop on strategies for preparing and writing the International English Languages Test (IELT) and prepared to follow up with another. We also designed a workshop led by admissions officers from an Ontario university on how to write a compelling university application essay or "statement."

For those students who were in our mentorship program, we provided leadership training and valuable volunteer experience. Our focus here was on training a core group of student volunteers in communication and leadership skills. Adhering to PAR principles, we sought and listened to our student mentors' input on what kinds of information was valuable to newly arrived ESA students and assigned them responsibility for organizing and leading the mentoring sessions. For example, students encouraged the team to include information on how the garbage/recycling system worked so that students would know where to put their trash. They also emphasized how confusing they found the local transit system, and as a result we included information about the transit system in our welcome package (see Figure 2). Many of our student mentors spoke glowingly of this opportunity as among the most positive experiences in their several years at Ravenswood. Just a few months later, several of the students who had arrived at the outset of the project volunteered to be mentors for the ESA cohort arriving midyear, attesting to the positive impact of this strategy.

\section{PAYING FOR THE TTC (BUS/SUBWAY/STREET CAR)}
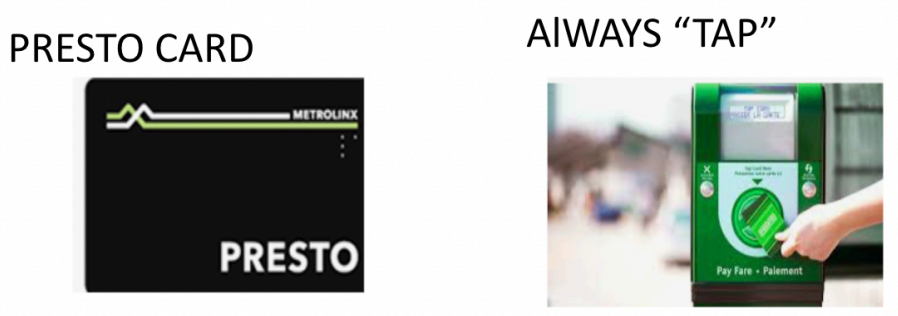

USE YOUR STUDENT I.D.
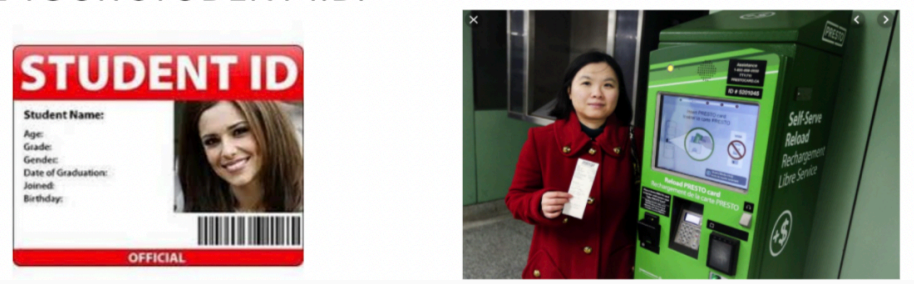

Figure 2. Navigating Local Transit 


\section{Discussion: Supporting STUdent LeARning and Wellness in an UNSTABle Schooling ConteXt}

While we find nothing exceptional about the orientations and activities elaborated in the preceding section, the fact that the project was able to maintain sufficient momentum to realize this agenda and create a positive school environment for a cohort of international students in such an unstable context is in itself exceptional. As explained, the year 2019 into 2020 was marked by constant disruptions and restrictions driven by shifts in staffing, escalating labour actions, and ultimately a lockdown due to a pandemic that forced all teaching online. Our action research team met these numerous challenges with resilience and creativity. For example, the team switched activities to lunchtime when "late start" mornings that had allowed flexibility to schedule workshops before classes started were cancelled. Inevitably, we were forced to abandon several of our initiatives as a result of changes in participating teachers' timetables that constrained their available time for planning and implementation. However, the curtailing of our original agenda did not prove as negatively dispositive as we might have anticipated. By the middle of the project, the team's focus on nurturing a caring, interactive environment had started to bear fruit, as attested by students and confirmed through our classroom and extra-classroom observations. Students continued to seek out the former school-based counsellor, after she returned to classroom teaching, during lunchtime and on breaks, and they also forged new relationships with members of our core team who were not their classroom teachers. Also, as noted, just 4 months after being newcomers, several ESAs signed up to be mentors for the next group of new students. Our study's funding, too, was helpful in underwriting time away from classes for members of our action research team who could then devote additional resources to planning and implementing academic and social supports for this cohort.

As we look to reconcile interpretations of the events and states of mind (as revealed in respondents' testimonies) recounted in this article within our theoretical frameworks, we have several summative observations. With regard to indicators of superdiversity, we found a receptiveness on the part of ESA students to engage with the English language and "Canadian ways" within the various extracurricular contact zones they encountered as a result of the support structures and multimodal resources orchestrated by members of our collaborative team. Here we are referencing, to be sure, experiential learning gained through students' participation in field excursions, where they were enveloped by riots of colours, tastes, sounds, and smells associated with their New World circumstancesresources they likely would not have encountered on their own because of linguistic, social, and cultural barriers, in addition to time constraints. This said, we hold that the most important contact zone for the acquisition of cultural knowledge on the part of students who participated in our project was the supportive environment created by caring professionals within Ravenswood Secondary School. It was within the school's walls that ESA students were introduced to cultural practices and mores revolving around concepts such as peer mentorship, borrowing and ownership, unions and labour unrest -with some of these ideas even finding their way into students' university application essays. 


\section{Conclusion: Revisioning a Pedagogy of Social Contact}

Having revisited our initial frameworks in light of our study's findings, we would nonetheless acknowledge that while these frameworks dovetail with the goals of our action research study, they do not wholly account for the events and circumstances that transpired over the 14-month collaboration. This is because we could not anticipate the central dilemma attached to our study's findings. Reflecting back, it is clear that the large majority of strategies we identified as effective in promoting ESA students' social integration through cultivation of cultural literacy and resourcefulness skills involved faceto-face interaction among study participants. We viewed-and continue to view-building a sense of social connection among and with ESA students as key to their academic engagement and sociocultural inclusion. Consequently, we actively pursued a pedagogy of social contact. From our project's most formal academic exercise to our silliest game, our agenda unfolded in a context of interpersonal interaction, both within and outside the school setting; and we are convinced that it is this pedagogy of social contact that closed the gap for our ESA students. While we were tasked with negotiating around systemic restructuring and labour countermoves, we did not contemplate at the outset that the option of face-to-face interaction would be taken off the table; nor did we seriously consider how we might build a learning context for these students were an apocalyptic scenario to present that rendered this option impossible. However, we are at this place now. And while we are confident that our co-participants in a PAR initiative (now funded through another source) care as much at this time about their ESA students as they did when the events recounted in this article took place, we have derived as a key insight from our engagement in this work that the mode through which this caring is currently transmitted is not nearly as effective as face-to-face communication in establishing a connection that mitigates the loneliness and alleviates the stresses of negotiating a strange educational system in a place far away from home. Nor can the development of educators' technological skills which provide convenient access to online modes of teaching and learning compensate for this profound absence of interpersonal communion within social spaces.

Therefore, within the convoluted politics of the commodification of international education (Buckner \& Stein, 2020), we must contend with a jarring contingency. Early study abroad students are faced with minimal or no face-to-face contact as they study, either masked in truncated classroom contexts or online from their local residences or home countries across time zones. These challenges are additionally compounded by their need to master subject matter curriculum-math, science, history, and so on-in a foreign language. And while the findings of this study provide evidence that committed and responsive educators are able to negotiate across various spectra-time, resources, teacher and student agencyto accommodate these youths' learning, socialization, and acculturation needs, we have scant evidence that the basic comforts of human contact may be circumvented for these adolescent learners. As one of our PAR team members expressed poignantly, "Someone needs to take responsibility for the fact that they're kids."

And so, we find ourselves back at the drawing board, exploring alternative strategies for negotiating curricular content in tandem with community-building, and attempting, across electronic channels, to anticipate the needs and circumstances of students whose names are 
harder to recall absent face-to-face contact. Daily, our PAR colleagues plumb the social and linguistic opportunities embedded within online forums such as Google Chats, Bamboozle, and TikTok and online games they creatively modify to underscore commonalities, as we brace for the next shoe to drop. As for the Ontario Ministry of Education's elusive vision of promoting intercultural exchange, we are nowhere in the neighbourhood of realizing this objective, though we may comfort ourselves with the knowledge that we had barely scratched the surface with regard to this priority before the advent of Covid-19. Given the current circumstances, we might instead set our sights on more realistic goals: creating caring schooling environments for early study abroad students (Noddings, 1984, 1992), places that allow students to move back and forth between the familiar tropes of home language and sociocultural traditions and contact zones where seminal aspects of their New World environment needed to access opportunities for employment and higher education may be encountered and cultivated.

\section{NoTES}

1. This project was supported by a Partnership Engage Grant from the Social Sciences and Research Council of Canada to the first author. The authors wish to thank the educators and guidance counsellors at Ravenswood who were part of the collaborative team for their creative work on program design and implementation and their tireless efforts to create a welcoming and inclusive climate for international students. We also express sincere gratitude to the students who participated in our project activities and whose focus group contributions made and will continue to make a positive difference in the lives of ESA students.

2. We were in the process of engaging students in translating the poster into several languages when the pandemic struck.

\section{REFERENCES}

Bhabha, H. (1994). The location of culture. Routledge.

Blommaert, J. (2013). Ethnography, superdiversity and linguistic landscapes: Chronicles of complexity. Multilingual Matters.

Blommaert, J., \& Rampton, B. (2011). Language and superdiversity. Diversities, 13(2), 1-21. http://newdiversities.mmg.mpg.de/?page_id=2056

Boeje, H. (2010). Analysis in qualitative research. Sage.

Bourdieu, P. (1977a). Outline of a theory of practice (R. Nice, Trans.). Cambridge University Press. (Original work published 1972)

Bourdieu, P. (1977b). The economics of linguistic exchanges. Social Science Information, 16(6), 645-668. https://doi.org/10.1177/053901847701600601 
Buckner, E., \& Stein, S. (2020). What counts as internationalization? Deconstructing the internationalization imperative. Journal of Studies in International Education, 24(2), 151-166. https://doi.org/10.1177/1028315319829878

Butler, J. (1999). Gender trouble: Feminsm and the subversion of identity (2nd ed.). Routledge.

Canagarajah, A. S. (2007). Lingua franca English, multilingual communities, and language acquisition. Modern Language Journal, 91, 923-938. https://doi.org/10.1111/j.15404781.2007.00678.x

Chen, J. M. (2017). Three levels of push-pull dynamics among Chinese international students' decision to study abroad in the Canadian context. Journal of International Students, 7(1), 113-135. https://doi.org/10.32674/jis.v7i1.248

Cummins, J., \& Early, M. (Eds.). (2011). Identity texts: The collaborative creation of power in multilingual schools. Trentham Books.

de Certeau, M. (1997). Culture in the plural (T. Conley, Trans.). University of Minnesota Press.

Eckert, P. (2000). Language variation as social practice: The linguistic construction of identity in Belten High. Blackwell.

García, O. (2009). Education, multilingualism and translanguaging in the 21st century. In T. Skutnabb-Kangas, R. Phillipson, A. K. Mohanty, \& M. Panda (Eds.), Social justice through multilingual education (pp. 140-158). Multilingual Matters.

García, O., \& Wei, L. (2013). Translanguaging: Language, bilingualism and education. Palgrave Macmillan.

Gee, J. (1999). The New Literacy Studies: From "socially situated" to the work of the social. In D. Barton, M. Hamilton, \& R. Ivanič (Eds.), Situated literacies: Reading and writing in context (pp. 180-196). Routledge.

Gillis, A., \& Jackson, W. (2002). Research methods for nurses: Methods and interpretation. Davis.

Global Affairs Canada. (2019). Building on success: International education strategy, 20192024. Government of Canada. https://www.international.gc.ca/education/assets/ pdfs/ies-sei/Building-on-Success-International-Education-Strategy-2019-2024.pdf

Goetz, J., \& Lecompte, M. (1984). Ethnography and qualitative design in educational research. Academic Press. 
Gupta, A., \& Ferguson, J. (Eds.). (1997). Culture, power, place: Explorations in critical anthropology. Duke University Press.

Gutiérrez, K. D., Baquedano-López, P., \& Tejeda, C. (1999). Rethinking diversity: Hybridity and hybrid language practices in the third space. Mind, Culture, and Activity, 6(4), 286303. https://doi.org/10.1080/10749039909524733

Heller, M. (2003). Globalization, the new economy, and the commodification of language and identity. Journal of Sociolinguistics, 7, 473-492. https://doi.org/10.1111/j.14679841.2003.00238.x

Hull, G. A., Stornaiuolo, A., \& Sahni, U. (2010). Cultural citizenship and cosmopolitan practice: Global youth communicate online. English Education, 42(4), 331-367.

Johnson, L., Seifen-Adkins, T., Sandhu, D., Arbles, N., \& Makino, H. (2018). Developing culturally responsive programs to promote international student adjustment: A participatory approach. Journal of International Students, 8(4), 1865-1878.

Kemmis, S., \& McTaggart, R. (2005). Participatory action research: Communicative action and the public sphere. In N. K. Denzin \& S. Y. Lincoln (Eds.), The Sage handbook of qualitative research (3rd ed., pp. 559-604). Sage.

Kress, G. (2002). Literacy in the new media age. Routledge.

Kuo, B. C. H., \& Roysircar, G. (2004). Predictors of acculturation for Chinese adolescents in Canada: Age of arrival, length of stay, social class, and English reading ability. Journal of Multicultural Counselling and Development, 32(3), 143-154. https://doi.org/10. 1002/j.2161z-1912.2004.tb00367

Kuo, B., \& Roysircar, G. (2006). An exploratory study of cross-cultural adaptation of adolescent Taiwanese unaccompanied sojourners in Canada. International Journal of Intercultural Relations, 30(2), 159-183. https://doi.org/10.1016/j.ijintrel.2005.07.007

Little, D., Leung, C., \& Van Avermaet, P. (Eds.). (2013). Managing diversity in education: Languages, policies, pedagogies. Multilingual Matters.

Liu, W. (2016). The international mobility of Chinese students: A cultural perspective. Canadian Journal of Higher Education, 46(4), 41-59. https://doi.org/10.47678/cjhe.v46 i4.186143

MacDonald, C. (2012). Understanding participatory action research: A qualitative research methodology option. Canadian Journal of Action Research, 3(2), 34-50. https://doi.org/10.33524/cjar.v13i2.37 
Maguire, P. (1987). Doing participatory action research: A feminist approach. University of Massachusettts, Center for International Education.

Nelson, J. (2013). What is the impact of international transition on social emotional health: A case study of East Asian international students in the Coquitlam School District [Unpublished master's research paper, Simon Fraser University]. Simon Fraser University Summit. http://summit.sfu.ca/item/13193

Noddings, N. (1984). Caring: A feminine approach to ethics and moral education. University of California Press.

Noddings, N. (1992). The challenge to care in schools: An alternative approach to education. Teachers College Press.

Ontario Ministry of Education. (2015). Ontario's strategy for K-12 international education. http://www.edu.gov.on.ca/eng/policyfunding/strategyK12.pdf

Pennycook, A. (2010). English and globalization. In J. Maybin \& J. Swann (Eds.), The Routledge companion to English language studies (pp. 113-121). Routledge.

Popadiuk, N. E. (2009). Unaccompanied Asian secondary students studying in Canada. International Journal for the Advancement of Counselling,31(4), 229-243. https://doi.org/10.1007/s10447-009-9080-6

Popadiuk, N. E. (2010). Asian international student transition to high school in Canada. Qualitative Report, 15(6), 1523-1548.

Popadiuk, N. E., \& Marshall, S. (2011). East Asian international secondary student experiences as learners of English as an additional language. Canadian Journal of Counselling, 45(3), 220-239. https://cjc-rcc.ucalgary.ca/cjc/index.php/rcc/article/ view/966

Poplack, S. (1980). "Sometimes I'll start a sentence in Spanish y termino en español": Toward a typology of codeswitching. Linguistics, 18, 581-618. https://doi.org/1 0.1515/ling.1980.18.7-8.581

Pratt, M. (1987). Linguistic utopias. In N. Fabb, D. Attridge, A. Durant, \& C. MacCabe (Eds.), The linguistics of writing: Arguments between language and literature (pp. 48-66). Methuen.

Rowsell, J. (2012). Artifactual English. In M. Grenfell, D. Bloome, C. Hardy, K. Pahl, J. Rowsell, \& B. Street (Eds.), Language, ethnography, and education: Bridging New Literacy Studies and Bourdieu (pp. 110-131). Routledge. 
Schecter, S. R. (2015). Language, culture and identity. In F. Sharifian (Ed.), The Routledge handbook of language and culture (pp. 196-208). Routledge.

Schecter, S. R. (2019). International students in Ontario secondary schools: How the stereotypes mislead [Paper presentation]. International Society for Language Studies conference, Hong Kong.

Schecter, S. R., \& Bayley, R. (2002). Language as cultural practice: Mexicanos en el norte. Lawrence Erlbaum Associates.

Schecter, S. R., \& Bayley, R. (2004). Language socialization in theory and practice. International Journal of Qualitative Studies in Education, 17(3), 605-625.

Schecter, S. R., Rashkovsky, K., \& Atari, Y. (2021). Using place-referenced approaches to extend language minority youths' problem solving abilities and literate engagement. Urban Education, 56(5), 772-802. https://doi.org/10.1177/0042085917714514

Spivak, G. (1993). Outside in the teaching machine. Routledge.

Street, B. (1995). Social literacies. Longman.

Street, B. (2005). Literacies across educational contexts: Mediating learning and teaching. Caslon.

Street, B., \& Leung, C. (2010). Sociolinguistics, language teaching and New Literacy Studies. In N. H. Hornberger \& S. L. McKay (Eds.), Sociolinguistics and language education (pp. 290-316). Multilingual Matters. https://doi.org/10.21832/9781847692849-013

Tamtik, M. (2019). School-aged children and decisions for studying abroad in Canada. International Journal of Educational Management, 33(5), 1052-1064. https://doi.org/10.1108/IJEM-05-2018-0156

Timperley, H., \& Alton-Lee, A. (2008). Reframing teacher professional learning: An alternative policy approach to strengthening valued outcomes for diverse learners. Review of Research in Education, 32(1), 328-369. https://doi.org/10.3102 /0091732X07308968

Vertovec, S. (2007). Super-diversity and its implications. Ethnic and Racial Studies, 29(6), 1024-1054. https://doi.org/10.1080/01419870701599465

Vertovec, S. (2010). Towards post-multiculturalism? Changing communities, contexts and conditions of diversity. International Social Science Journal, 61(199), 83-95. https://doi.org/10.1111/j.1468-2451.2010.01749.x 
Wong, S. T., Homma, Y., Johnson, J., \& Saewyc, E. (2001). The unmet health needs of east Asian high school students: Are homestay students at risk?. Canadian Journal of Public Health, 101(3), 241-245. https://doi.org/10.17269/cjph.101.2358

Xing, L., \& Zhou, L. (2018, February 22). "The system is full of holes": Experts say young foreign students left vulnerable by unregulated industry. CBC News. http://www.cbc.ca/news/canada/toronto/underage-visa-students-falling-throughcracks-in-canada- 1.4525664

Yi, Y. (2013). Adolescent multilingual writer's negotiation of multiple identities and access to academic writing: A case study of a Jogi Yuhak student in a US high school. Canadian Modern Language Review, 69(2), 207-231. https://doi.org/10.3138/cmlr.1381

Zentella, A. C. (1998). Multiple codes, multiple identities: Puerto Rican children in New York City. In S. M. Hoyle \& C. T. Adger (Eds.), Kids talk: Strategic language use in later childhood (pp. 95-112). Oxford University Press.

Zheng, S. (2014). Academic achievement, school engagement, and well-being of international/visa students in the Toronto School Board's secondary schools (Research Report No. 13/14-09). Toronto District School Board.

\section{BIOGRAPHICAL NOTE:}

Sandra R. Schecter is professor of education and applied linguistics at York University. An ethnolinguist, she conducts research on language and literacy education and language planning in the context of bi- and multi-lingual societies. Her publications include the coauthored (with Jim Cummins) Multilingual Education in Practice: Using Diversity as a Resource (Heinemann) and the co-edited (with Lucinda Pease-Alvarez) volume Learning, Teaching and Community: Contributions of Situated and Participatory Approaches to Educational Innovation (Lawrence Erlbaum).

Nancy Bell is a PhD candidate in education at York University, where she is conducting ethnographic research on international students in Ontario. Her academic interests include second language learning, literacy, and policy studies. She has taught at the Toronto District School Board for over ten years, and has held school leadership positions in ESL teaching and literacy. Nancy has an MEd with a diploma in language and literacy, a BEd, and an MA in history, and is a member of the Ontario College of Teachers. She is a sessional instructor at Ontario Institute for Studies in Education at the University of Toronto. 